\title{
An Empirical Study on the Demand of Air Passenger Transport and Regional Economic Development in Inner Mongolia
}

\author{
Yong Gui ${ }^{1,2, *}$, Zhang Jing ${ }^{1}$, Su Nuoer ${ }^{1}$ \\ ${ }^{1}$ School of Statistics and Mathematics, Inner Mongolia University of Finance and Economics, Hohhot, China \\ ${ }^{2}$ Inner Mongolia Key Laboratory of Economic Data Analysis and Mining, Inner Mongolia University of Finance and Economics, Hohhot, \\ China
}

\section{Email address:}

nmyonggui@163.com (Yong Gui), zhangjing_lux@163.com (Zhang Jing), sunuoer666@163.com (Su Nuoer)

${ }^{*}$ Corresponding author

\section{To cite this article:}

Yong Gui, Zhang Jing, Su Nuoer. An Empirical Study on the Demand of Air Passenger Transport and Regional Economic Development in Inner Mongolia. Science Innovation. Vol. 9, No. 5, 2021, pp. 182-188. doi: 10.11648/j.si.20210905.11

Received: August 11, 2021; Accepted: September 27, 2021; Published: September 30, 2021

\begin{abstract}
As an important part of the comprehensive transportation system, air transportation is the key link connecting regional exchanges. And air transportation can actively promote the development of regional economy. In this paper, the airport operation and regional economy of the leagues and cities in Inner Mongolia are taken as the research object, the co-integration and Granger causality between the air passenger throughput (TQ) and regional gross domestic product (GDP) of the leagues and cities are analyzed, and the correlation between air passenger throughput and regional gross domestic product is discussed. It is found that there is co-integration relationship between the air passenger throughput and regional gross domestic product in seven cities. The League cities with co-integration relationship are Hohhot City, Ordos City, Baotou City, Tongliao City, Xilin Gol League, Hulunbuir City and Bayannur City. In Granger causality analysis, regional gross domestic product of Hohhot City, Baotou City, Hulun Buir City, Tongliao City, Chifeng City and Bayannur City, Xilin Gol League and Hinggan League is the Granger cause of air passenger throughput, and vice versa. regional gross domestic product and air passenger throughput of Ordos City are mutually Granger causality. In general, regional economic development plays a more significant role in promoting the growth of air transport. Through comparative study, it is found that regional economic development can better promote the growth of air transport in Tongliao City.
\end{abstract}

Keywords: Co-integration Analysis, Granger Causality Analysis, Regional Airport, Regional Economy

\section{内蒙古航空客运需求与区域经济发展关系的实证研究}

\author{
永贵 $^{1,2 *}$, 张静 ${ }^{1}$ ，苏诺尔 ${ }^{1}$ \\ ${ }^{1}$ 内蒙古财经大学统计与数学学院, 呼和浩特, 中国 \\ ${ }^{2}$ 内蒙古经济数据分析与挖掘重点实验室, 呼和浩特, 中国
}

邮箱

nmyonggui@163.com（永贵）, zhangjing_lux@163.com（张静）, sunuoer666@163.com（苏诺尔）

摘要: 航空运输作为综合交通运输体系的重要组成部分, 是连接地区间交流的关键纽带, 对推动区域经济发展具有积
极作用。本文以内蒙古各盟市机场运营与区域经济发展为研究对象, 分析各盟市的航空旅客吞吐量 (TQ) 与地区生产
总值 (GDP) 间的协整性及格兰杰因果关系, 探讨两者之间的关联性。研究发现, 有七个盟市的航空旅客吞吐量与GDP
之间存在协整关系, 分别是呼和浩特市、鄂尔多斯市、包头市、通辽市、锡林郭勒盟、呼伦贝尔市和巴彦淖尔市。在 
格兰杰因果关系的分析中, 呼和浩特市、包头市、呼伦贝尔市、通辽市、锡林郭勒盟、巴彦淖尔市、赤峰市和兴安盟 的GDP是航空旅客吞吐量的格兰杰原因, 反之不是。鄂尔多斯市的GDP与航空旅客吞吐量互为格兰杰因果关系。总体 来说区域经济发展对航空运输增长的促进作用更加显著, 对比研究发现通辽市的区域经济发展更能促进航空运输增长。

关键词：协整分析，格兰杰因果分析，区域机场，区域经济

\section{1. 引言}

西部大开发战略是中国应对经济发展区域协调难 题的重大举措。为解决区域协调问题，使中国经济又好 又快发展，政府将东部沿海地区的剩余经济发展能力， 用来提高西部地区经济社会的发展水平。党中央、国务 院在2000年先后印发的《关于实施西部大开发若干政策 措施的通知》中指出, 加快基础设施建设是西部开发的 主要任务之一, 要以强化基础设施规划建设为抓手, 夯 实西部地区经济社会发展基础。在交通设施方面, 重点 提高通达度、通畅性和均等化水平, 加强横贯东西、纵 贯南北的运输通道建设, 拓展区域开发轴线, 积极发展 西部航空枢纽建设。航空运输作为综合交通运输体系的 重要组成部分, 相对于公路、铁路等交通运输方式, 具 有不受地形条件约束的特点, 且发展航空交通所需的投 资额相对较小, 建设周期短, 见效快。积极发展航空运 输, 有利于在短时间内沟通西部地区与沿海经济发达地区 以及周边国家的联系。由于西部地区多山地、多高原的地 理特性所决定, 在西部地区的陆路交通尚未形成良好的运 输网络和运输能力前, 西部大部分地区航空运输的发展在 西部综合交通运输体系中将一直处于重要地位。

在西部大开发的 20 年历程中, 西部大开发战略显著 促进了西部地区经济的增长与航空运输的发展。进入新 时代以来, 我国经济已经开始由以数量型增长为主逐渐 转变为以质量型增长为主。新时代推进西部大开发战略, 有利于形成区域协调大发展的新格局, 能够良好地解决 西部地区发展不平衡不充分的问题。中共中央、国务院 在2020年颁布的《关于新时代推进西部大开发形成新格 局的指导意见》文件中指出, 新时代应以建设社会主义 现代化强国为战略目标来推进西部大开发战略, 在加强 横贯东西、纵贯南北的运输通道建设, 拓展区域开发轴 线的同时，仍需加强航空口岸和枢纽建设，扩大枢纽机 场航权，积极发展通用航空。同时内蒙古自治区党委在 关于《自治区人民政府关于新时代推进西部大开发形成 新格局的实施意见》中指出, 在强化机场建设发展方面, 应推进呼和浩特区域枢纽机场建设, 支持有条件的旗县 建设通用机场, 并且扩大多层次对外开放, 支持二连浩 特铁路口岸功能向乌兰察布延伸, 推动包头、二连浩特 等航空口岸常年开放。

随着西部大开发战略的开展与实施, 内蒙古自治区的 经济建设得到了快速的发展, 内蒙古1999年的地区生产总 值为 1268.10 亿元, 到 2019 年达到了 17212.53 亿元, 增加了 13.57倍。机场作为重要的综合交通运输枢纽, 在提高交 通运输效率、促进旅游业发展和产业聚集等方面发挥着巨 大的作用。随着人民生活水平的提高, 居民不仅对交通出
行的需求越来越大, 而且在出行方式的选择上也有所改变。 在生活节奏正不断加快的今天, 相对于路途远、耗时长的 铁路运输和公路运输, 更加方便快捷的航空运输方式被越 来越多的人选择。内蒙古航空运输客运量从1999年的 98 万人, 到2019年达到了 1443 万人, 增加了 14.72 倍。

为更好的实现交通运输与区域经济间的协调发展, 很 多学者利用现代计量经济学的投入产出[1]、灰色关联度 [2]、向量误差修正模型[3]、VAR模型[4]、协整及格兰杰 因果关系检验 [5-6]等方法进行了大量研究。为分析机场运 输和区域经济发展间的动态关联, 探索机场与经济发展之 间的相互作用, 大量的研究集中在机场的投资建设以及机 场运营与经济发展间的关系分析, 如Huddleston等人的研 究显示, 机场的建设投资会导致地区经济的增长 [7]; Debbage的研究结果表明, 对机场建设的直接投资, 不仅 能够增加地区GDP, 并且可以增加更多的投资机会和就业 机会从而促进经济的增长 [8]; Green的研究认为投资建设 机场的社会效益能够向外辐射较大的区域, 并且机场是促 进地区经济发展的主要因素[9]。在机场的投资建设对区域 经济发展的关系研究中, 其结果均表明加强机场的投资建 设能够有利地促进区域经济的发展。

机场与区域经济关联紧密, 掌握二者间的内在关联, 能够对机场进行合理定位, 对实现机场与区域经济间的 协调发展具有重要意义。内蒙古航空运输的发展, 对推 动内蒙古经济社会的发展和综合交通体系的完善具有重 要的促进作用。在机场运营与经济发展间的相互关系方 面, 国内外学者做了大量研究, 如Baker对澳大利亚 1986-2011年88个支线机场对区域经济增长的影响, 通过 实证分析发现机场与区域经济间存在双向的格兰杰因果 关系[10]; Button考察了美国的航空运输对促进区域经济 发展发挥的潜在作用, 分析了美国 32 个城市中 35 个机场 的统计数据, 发现航空货物运输是经济发展的驱动力 [11]; Kasarda等人研究显示, 航空运输客货运量和区域GDP之 间有固定的数量关系 [12]; Marazzo等人的研究结论显示 巴西的 GDP 是航空旅客运量的格兰杰原因 [13];

Mahbubul等人通过对南亚地区 8 个国家的航空客运量与 经济发展的研究, 发现人均GDP对航空客运量有着长期 单向的因果关系 [14]; 李艳华对民航业和经济间的关系进 行的分析发现我国航空运输有助于提高经济水平 [15]; 申 惠、邹平研究发现民用航空运输与经济发展间存在着双 向的因果关系, 且经济对民用航空运输的促进作用相对 更加显著[16]; 王全良基于中国2001-2014年45个临空经 济区的面板数据, 利用格兰杰因果检验和动态空间计量 等实证分析方法, 得出了机场腹地区域的GDP是航空旅 客吞吐量的格兰杰原因的结论 [17]; Tolcha研究分析了 1981-2018年期间撒哈拉以南6个非洲国家的空运需求与 经济发展之间的因果关系, 研究结果揭示了相异地区的 
不同因果方向 [18]。综上所述, 在不同国家或地区的航空 运输与经济发展间关系的研究结论中, 这些因果关系有 单向的和双向的, 同时也会存在无法判断因果关系方向 的情况。但由于国家或省级水平上的经济发展状况更易 受到人们的关注, 因此以往学者们大都在国家或省级水 平上来进行航空运输与经济发展间的研究, 很少有研究 聚焦到地级市水平上。而每个省份是由多个地级市共同 组成的, 只有当一个省份的每个地级市都得到良好的发 展, 这个省份才能完全的发展壮大, 所以对地级市水平 上航空运输与经济发展的研究是很有必要的。

在新时代西部大开发战略下, 有必要全面分析内蒙古 航空客运需求和区域经济发展现状, 为相关政策的制定与 实施提供参考。为此, 本文针对内蒙古的航空运输与经济 发展, 选取内蒙古 12 个盟市 (即呼和浩特市、包头市、鄂 尔多斯市、呼伦贝尔市、通辽市、赤峰市、巴彦淖尔市、 乌海市、乌兰察布市、兴安盟、锡林郭勒盟和阿拉善盟） 的机场为研究对象, 将内蒙古各盟市机场的航空旅客吞吐 量和地区生产总值分别作为盟市机场的发展和区域经济 的评价指标, 对其进行协整性及格兰杰因果关系的研究, 探讨内蒙古各盟市机场与区域经济的相互作用关系, 并分 析不同盟市之间的差异性, 以期为地方政府制定航空发展 政策提供参考。

\section{2. 研究对象及数据处理}

\section{1. 研究对象}

内蒙古自治区位于中国北部边疆地区，地域辽阔，东 西跨度直线距离长达 2400 公里, 南北最大跨度 1700 公里, 其特殊的地理位置与地貌特征都在一定程度上限制了内 蒙古经济的发展。航空运输具有速度快、机动性大、基本 建设周期短等优点, 具有高速公路和铁路不可替代的优势。 因此如何实现航空运输与区域经济间的协调发展, 成为一 大研究主题, 从图1可以看出二者在2008-2019年一直保持 着持续增长的趋势。内蒙古地区实际GDP从 2008 年的 7736.20亿元达到2019年的21654.51亿元, 内蒙古机场旅客 吞吐量从 2008 年的 397.26 万人次达到 2019 年的 2754.04 万 人次, 分别实现了 2.29 倍和 6.93 倍的增长。

区域经济的发展促进产业的结构优化, 内蒙古第一、 二产业比重逐年降低，第三产业贡献率从2008年44.6\%增 长至2019年的 $49.6 \%$ 。内蒙古航空发展水平的提高, 推动 内蒙古航空运输客运量不断增长。据中国民航局统计, 2019年内蒙古旅客吞吐量较2018年同比增长 $8.9 \%$, 位居全 国12名, 在西部地区省份中排第6名。区域经济作为航空 运输业发展的基础, 其经济发展水平的高低直接影响航空 运输量的需求变化。航空运输需求增加, 能够提高信息、 物流等经济发展核心资源的交互效率, 为区域经济发展提 供强大的助推力。航空运输需求与区域经济发展间的相互 作用和影响, 启示我们认识两者良性互动发展的重要性。 那么内蒙古 12 个盟市的生产总值与各机场的航空旅客吞 吐量发展现状如何, 且它们之间是否存在协整关系, 以及 存在怎样的因果关系, 均是本文探讨的重点。

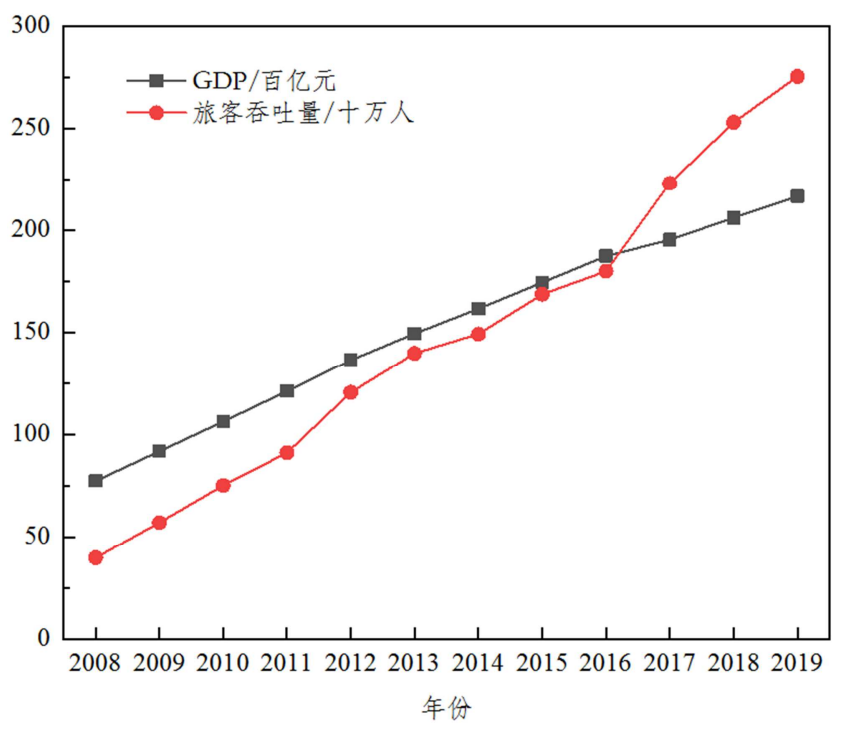

图1 内蒙古地区实际GDP与旅客吞吐量趋势图。

\section{2. 数据处理}

本文利用内蒙古 12 个盟市的航空旅客吞吐量和地区 生产总值, 对内蒙古各盟市的航空运输与区域经济发展的 关系进行了研究。由于盟市数据的可获得性, 本文选取了 2008-2019年的数据。数据来源于全国民航机场统计年报 和内蒙古各盟市年度统计年鉴。机场的选取包括呼和浩特 市白塔国际机场, 鄂尔多斯市伊金霍洛机场, 呼伦贝尔市 东山机场、满洲里西郊机场和扎兰屯/成吉思汗机场, 包 头市二里半机场, 赤峰市玉龙机场, 通辽市通辽机场和霍 林郭勒机场, 兴安盟的义勒力特机场和伊尔施机场, 锡林 郭勒盟的锡林浩特机场和赛乌素机场, 巴彦淖尔市天吉泰 机场, 乌海市的乌海机场, 乌兰察布市集宁机场, 阿拉善 盟的巴彦浩特机场、桃来机场和巴丹吉林机场。

首先, 为消除价格因素对GDP的影响, 利用GDP指数 将名义GDP换算为实际GDP, 以便更好地反映地区经济发 展的实际状况。其次, 将内蒙古各盟市的实际GDP与机场 旅客吞吐量数据取对数, 消除时间序列数据易产生异方差 的影响。

\section{3. 总体趋势分析}

由图2所示, 内蒙古 12 个盟市的实际GDP呈现逐年增 加的趋势, 各盟市间地区生产总值存在一定的差异。包头 市是实际GDP增长最快的地区, 在2019年达到4457.37亿 元; 然后依次是鄂尔多斯市和呼和浩特市, 在2019年分别 达到4262.68亿元和3227.77亿元; 而阿拉善盟和兴安盟是 实际GDP增长速度最慢的两个地区, 在 2019 年分别为 476.67 亿元和 433.94 亿元。

由图3所示 (呼和浩特市航空旅客吞吐量在次纵坐标 中显示），2008-2019年内蒙古12个盟市的航空旅客吞吐 量呈现逐年增长的趋势, 2019年呼和浩特市的航空旅客吞 吐量达到 1315.18 万人次, 而后依次是呼伦贝尔市、鄂尔 多斯市、包头市和赤峰市均超过 150 万人次, 但相比呼和 浩特市的年航空旅客吞吐量仍有较大的差距。而航空旅客 吞吐量最低的地区是阿拉善盟和乌兰察布市, 这主要是因 
为这两个地区的机场分别于 2013年和2016年才开始正式 通航，机场建成时间晚、通航时间短，所以航线少、航班 频率低, 从而导致了航空旅客吞吐量较低。

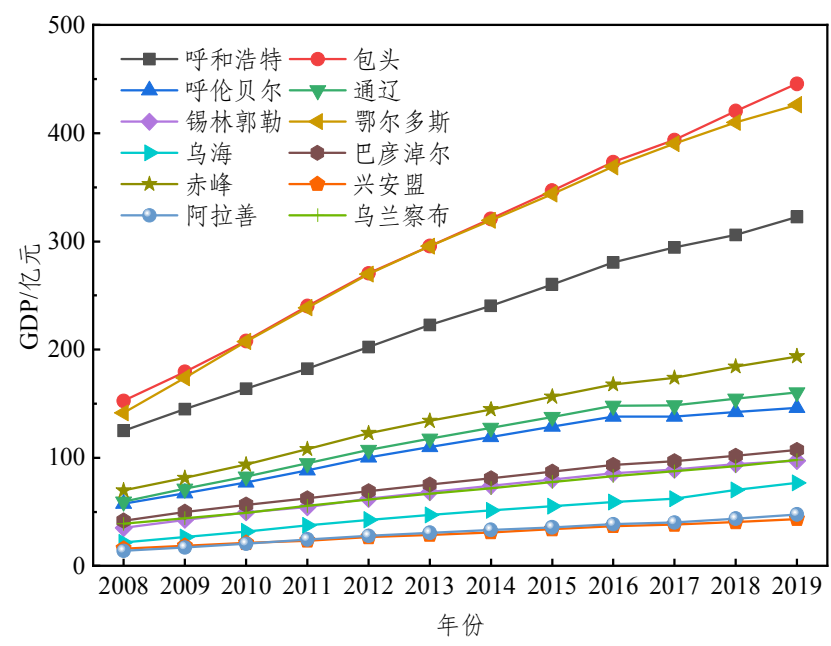

图2 内蒙古 12 个盟市实际GDP趋势图。

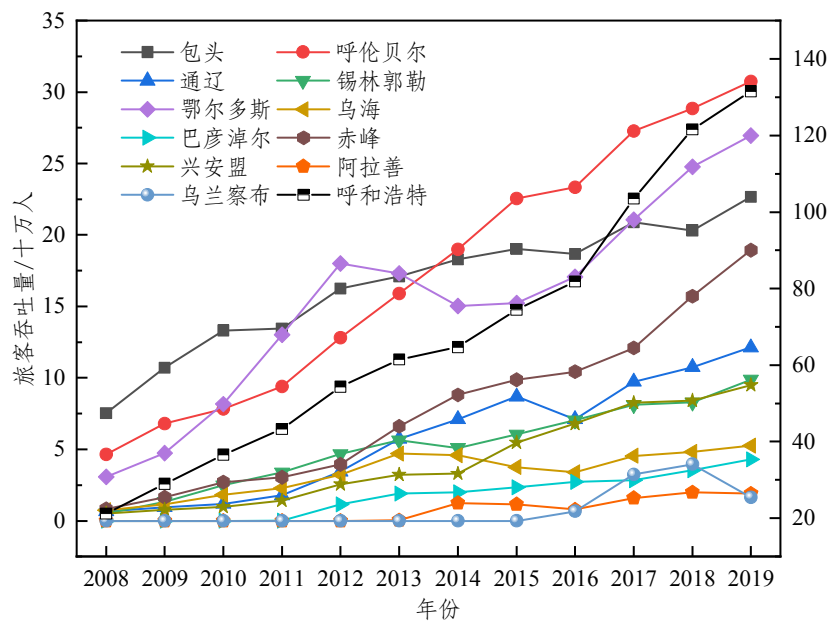

图3 内蒙古 12 个盟市航空旅客吞吐量趋势图。

\section{3．盟市间的协整分析}

\section{1. 单位根检验}

由于阿拉善盟和乌兰察布市的机场建设较晚, 航班开 通时间短, 故获取的数据较少, 不适宜进行协整分析, 因 此, 下面对其它 10 个盟市的实际GDP与机场旅客吞吐量的 对数序列进行协整分析。在进行协整性检验与格兰杰因果 检验前, 首先通过公式 (1) 的 $\mathrm{ADF}$ 检验方程对数据进行 单位根检验。

$$
\Delta y_{t}=x_{t}^{\prime} \beta+\delta y_{t-1}+\sum_{i=1}^{k} \alpha_{t} \Delta y_{t-i}+\varepsilon_{t}
$$

公式 (1) 中 $\alpha 、 \beta$ 和 $\delta$ 是要估计的参数, $\varepsilon$ 为随机 扰动项, $\Delta$ 是一个差分算子。若检验的结果为拒绝零假设 $\left(H_{0}: \delta=0\right)$ ， 则存在单位根, 即序列非平稳。
由表 1 所示, 第三、四列为 10 个盟市对数序列的 ADF 检验结果, 可以看出赤峰市和兴安盟地区的对数序列是平 稳的。而呼和浩特市、包头市等其余 8 个盟市的实际GDP 与航空旅客吞吐量的对数序列都为非平稳序列, 接下来分 别对其进行一阶差分后再进行ADF检验。由表一中第五、 六列显示的检验结果可知, 它们的一阶差分序列为平稳序 列, 因此这 8 个盟市的实际GDP与航空旅客吞吐量的对数 序列均为一阶单整。

表1 ADF检验结果汇总表。

\begin{tabular}{llllll}
\hline & 对数序列 & & \multicolumn{3}{c}{ 差分序列 } \\
\cline { 2 - 6 } & & ADF值 & P值 & ADF值 & P值 \\
\hline 呼和浩特市 & lngdp1 & -0.779 & 0.8252 & -4.804 & 0.0005 \\
& lntq1 & -1.123 & 0.7060 & -2.608 & 0.0156 \\
包头市 & lngdp2 & -2.024 & 0.2760 & -4.232 & 0.0006 \\
呼伦贝尔市 & lntq2 & -2.853 & 0.0511 & -4.728 & 0.0001 \\
& lngdp3 & -2.539 & 0.1062 & -5.205 & 0.0001 \\
通辽市 & lntq3 & -2.692 & 0.0755 & -4.292 & 0.0032 \\
锡林郭勒盟 & lngdp4 & -1.461 & 0.8422 & -4.045 & 0.0076 \\
鄂尔多斯市 & lng44 & -1.695 & 0.4335 & -2.015 & 0.0394 \\
& lntq5 & -2.693 & 0.0753 & -4.785 & 0.0001 \\
巴彦淖尔市 & lngdp6 & -1.796 & 0.3824 & -3.514 & 0.0076 \\
& lntq6 & -1.541 & 0.5134 & -4.597 & 0.0010 \\
乌海市 & lngdp7 & -2.793 & 0.8211 & -8.326 & 0.0000 \\
& lntq7 & 0.288 & 0.0746 & -4.667 & 0.0008 \\
赤峰市 & lngdp8 & -0.839 & 0.9768 & -5.418 & 0.0000 \\
& lntq8 & -2.22 & 0.4789 & -2.053 & 0.0371 \\
兴安盟 & lngdp9 & -3.501 & 0.0080 & & 0.0497 \\
& lntq9 & -2.668 & 0.0379 & & \\
\hline
\end{tabular}

\section{2. 协整检验}

协整的基本思想是对于有单位根的变量, 传统的处理 方法是进行一阶差分, 但一阶差分后变量的经济含义与原 序列相比就发生了很大的改变, 所以如果多个单位根变量 之间由于某种经济力量而存在“长期均衡关系”, 使得这些 单位根序列拥有“共同的随机趋势”, 那么就可以对这些变 量做线性组合从而消除这种随机趋势。

通过表 1 的结果, 对具有一阶单整的 8 个盟市的数据进 行协整检验, 来确定这 8 个盟市的机场旅客吞吐量与实际 GDP之间是否存在协整关系。采用EG两步法对两个变量 进行协整检验, 方程 (2) 和方程 (3) 为通过最小二乘估 计得到EG方程:

$$
\begin{aligned}
& \ln T Q_{i}=\gamma_{i}+\eta_{i} \ln G D P_{i}+\epsilon_{i 1} \\
& \ln G D P_{i}=\alpha_{i}+\beta_{i} \ln T Q_{i}+\epsilon_{i 2}
\end{aligned}
$$

其中, $\alpha$ 和 $\gamma$ 是要估计的常数, $\beta$ 和 $\eta$ 是要估计的弹 性系数。

通过得到的EG方程所计算出残差序列, 并将其进行 平稳性检验。通过表 2 的残差序列 $\mathrm{ADF}$ 检验结果可以看出 乌海市的残差序列不平稳, 故乌海市的机场旅客吞吐量与 实际GDP的对数序列间不存在协整关系。因此内蒙古地区 机场航空旅客吞吐量和实际GDP之间存在协整关系的盟 
市分别有呼和浩特市、鄂尔多斯市、包头市、通辽市、锡 林郭勒盟、呼伦贝尔市和巴彦淖尔市这 7 个盟市。

表2 残差序列平稳性检验结果汇总表。

\begin{tabular}{llll}
\hline & & ADF值 & P值 \\
\hline 呼和浩特市 & e11 & -2.186 & 0.0325 \\
& e12 & -2.226 & 0.0307 \\
包头市 & e21 & -5.183 & 0.0001 \\
呼伦贝尔市 & e22 & -4.978 & 0.0002 \\
& e31 & -2.719 & 0.0149 \\
通辽市 & e32 & -2.376 & 0.0246 \\
锡林郭勒盟 & e41 & -2.878 & 0.0119 \\
鄂尔多斯市 & e42 & -2.650 & 0.0165 \\
& e52 & -1.646 & 0.0719 \\
巴彦淖尔市 & e61 & -1.879 & 0.0312 \\
乌海市 & e71 & -3.086 & 0.0276 \\
& e72 & -4.717 & 0.0001 \\
& $\mathrm{e} 81$ & -2.406 & 0.0477 \\
\hline
\end{tabular}

由EG方程中估计的参数 $\beta$ 和 $\eta$ 是反映变量间协整关系 的弹性系数 (表3)。地区经济增长对航空旅客吞吐量的弹 性系数最高的是包头市的 1.050 , 即航空旅客吞吐量每增加 $1 \%$, 地区经济增长 $1.050 \%$, 而弹性系数最低的是通辽市的 0.310 , 说明航空旅客吞吐量的增加对地区经济增长的促进作 用在包头市是最为显著的。而航空旅客吞吐量对地区经济增 长的弹性系数中最高的是通辽市的 3.120 , 即通辽市经济每增 加 $1 \%$, 航空旅客吞吐量增加约 $3.120 \%$, 而弹性系数最低的 是包头市为 0.891 。由此可以说明通辽市的经济增长对航空旅 客吞吐量的增加促进效果与其它盟市相比更为显著。
表3 EG方程弹性系数表。

\begin{tabular}{llllllll}
\hline $\mathbf{i}$ & $\mathbf{1}$ & $\mathbf{2}$ & $\mathbf{3}$ & $\mathbf{4}$ & $\mathbf{5}$ & $\mathbf{6}$ & $\mathbf{8}$ \\
\hline$\beta_{i}$ & 0.542 & 1.050 & 0.496 & 0.310 & 0.366 & 0.509 & 0.369 \\
$\eta_{i}$ & 1.811 & 0.891 & 1.989 & 3.120 & 2.538 & 1.774 & 2.599 \\
\hline
\end{tabular}

\section{3. 误差修正模型}

根据内蒙古各盟市机场的航空旅客吞吐量和地区实 际GDP之间的协整关系, 建立两变量的误差修正模型, 来 研究变量间的短期波动特征。误差修正模型如下:

$$
\begin{gathered}
d \ln G D P_{i}=\alpha_{i}+\theta_{i} d \ln T Q_{i}+e_{i 1} \\
d \ln T Q_{i}=\beta_{i}+\delta_{i} d \ln G D P_{i}+e_{i 2}
\end{gathered}
$$

误差修正项 $e_{i 1}$ 与 $e_{i 2}$ 系数的大小反映了对长期偏离的 调整力度, 通过对比各个盟市所得到的误差修正模型, 找 到最适宜的方程来解释变量间的关系。故呼和浩特市、鄂 尔多斯市选择公式 (4)模式的误差修正模型, 如表4所示, 他们的短期弹性系数分别为 -0.397 和 -0.155 , 即在 $5 \%$ 的显 著性水平下, 短期波动的偏离会以每期 $39.7 \%$ 和 $15.5 \%$ 的力 度作反向调整, 将非均衡状态拉回到均衡状态。包头市、 呼伦贝尔市、通辽市、锡林郭勒盟、巴彦淖尔市选择公式

（5）模式的误差修正模型，根据表 4, 在 $5 \%$ 的显著性水 平下它们短期波动的偏离分别以每期 $88.3 \%$ 、 $67.3 \%$ 、 $71.8 \% 、 46.7 \%$ 和 $133.5 \%$ 的力度作反向调整。

表4 误差修正项系数表。

\begin{tabular}{llllllll}
\hline $\mathbf{i}$ & $\mathbf{1}$ & $\mathbf{2}$ & $\mathbf{3}$ & $\mathbf{4}$ & $\mathbf{5}$ & $\mathbf{6}$ & $\mathbf{8}$ \\
\hline$e_{i 1}$ & -0.397 & & & & & -0.155 & \\
$e_{i 2}$ & & -0.883 & -0.673 & -0.718 & -0.467 & & -1.335 \\
\hline
\end{tabular}

\section{4. 格兰杰因果关系分析}

在格兰杰因果关系检验中, 其它条件不变, 如果一个变 量 $\mathrm{Y}$ 的滞后值可以提高另一个变量 $\mathrm{X}$ 的可预测性, 则 $\mathrm{Y}$ 被称为 $\mathrm{X}$ 的格兰杰原因。这种因果关系可能是单向的或双向的, 也 可能是不存在的。GDP与航空旅客吞吐量的格兰杰因果关系 回归检验式为公式 (6) 和公式 (7)，其中 $t$ 表示滞后期:

$$
\ln G D P_{t}=\sum_{i=1}^{p} \alpha_{i} \ln G D P_{t-1}+\sum_{i=1}^{p} \beta_{i} \ln T Q_{t-i}+u_{1 t}
$$

$$
\ln T Q_{t}=\sum_{i=1}^{p} \alpha_{i} \ln T Q_{t-1}+\sum_{i=1}^{p} \beta_{i} \ln G D P_{t-i}+u_{2 t}
$$

因为格兰杰因果关系的分析仅仅适用于具有协整关 系的单位根过程或者是平稳的时间序列, 因此应对具有协 整关系的 7 个盟市与原序列平稳的两个盟市（赤峰市、兴 安盟) 分别进行格兰杰因果检验。在进行格兰杰因果检验 前, 对建立的VAR模型的残差自相关性检验见表 5 。检验 的P值均在 $5 \%$ 的显著性水平上大于零, 即接受残差“无自 相关”的原假设, 认为扰动项为白噪声序列。

表5 残差自相关检验汇总表。

\begin{tabular}{lllllllll}
\hline 序号 & 滞后期 & P值 & 序号 & 滞后期 & P值 & 序号 & 滞后期 & P值 \\
\hline 1 & 1 & 0.5556 & 4 & 1 & 0.1079 & 8 & 1 & 0.7338 \\
& 2 & 0.4597 & & 2 & 0.5243 & & 2 & 0.2576 \\
2 & 1 & 0.9966 & 5 & 1 & 0.8876 & 9 & 1 & 0.3969 \\
& 2 & 0.0581 & & 2 & 0.0549 & & 2 & 0.8075 \\
3 & 1 & 0.3218 & 6 & 1 & 0.1938 & 10 & 1 & 0.3239 \\
& 2 & 0.4486 & & 2 & 0.8272 & & 2 & 0.7001 \\
\hline
\end{tabular}


通过格兰杰因果关系检验所得的结果，在 $5 \%$ 的显著 性水平下, 呼和浩特市、包头市、赤峰市、呼伦贝尔市、 通辽市、巴彦淖尔市、锡林郭勒盟和兴安盟的GDP是航空 旅客吞吐量的格兰杰原因, 鄂尔多斯市的GDP与航空旅客 吞吐量互为格兰杰因果关系, 由此可见, 鄂尔多斯市的区 域经济与航空运输间的发展对比其它盟市更为协调。

由表6给出的格兰杰因果关系检验结果可知, 呼和浩 特市的GDP是航空旅客吞吐量的格兰杰原因, 表明呼和 浩特市GDP对航空旅客吞吐量的作用更为显著, 这与表3 的结果相一致。呼和浩特市的GDP在 12 个盟市中排名第 三, 却拥有遥遥领先于其它盟市的航空旅客吞吐量, 这 是因为呼和浩特市作为内蒙古自治区的首府城市, 是全 区与外界联系的重要门户。呼和浩特白塔国际机场拥有 全区最多的通航城市和最多的航线条数（在2020年分别 达到 91 个通航城市和 154 条航线）。同时，呼和浩特市第 三产业GDP为 1853.41 亿元, 占总产值的 $66.40 \%, 2019$ 年规 模以上服务业实现营业收入633.68亿元, 占全区 $39.65 \%$, 均说明呼和浩特发展以服务业为主。服务业的发展也是 带动呼和浩特市航空客运需求的主要因素之一。同理, 包头市、通辽市、兴安盟、巴彦淖尔市、赤峰市、锡林 郭勒盟和呼伦贝尔市的区域经济对航空运输均有较明显 的促进作用, 存在GDP到航空旅客吞吐量方向上的格兰 杰原因。鄂尔多斯市的GDP与航空旅客吞吐量间存在双 向的格兰杰因果关系, 说明鄂尔多斯市的航空运输增长 与经济发展间的相互促进效果均比较显著。航空运输量 的增长代表着鄂尔多斯市交通基础设施得到了很好的改 善, 能够在需求方面降低平均运输成本从而增加运输次 数, 交通量的增加同样会导致运输能力的提高, 从而会 产生规模经济。因此, 航空运输交通的改善可以促进经 济的发展, 反之, 当经济得到发展, 人民的生活水平也 会随之提高, 由此会产生更多的出行行为 (如旅游、探 亲等), 增加航空出行需求。

表6 Granger因果检验结果表。

\begin{tabular}{|c|c|c|}
\hline 原假设 & 卡方统计量 & P值 \\
\hline ltq1不是lgdp1的格兰杰原因 & 3.2297 & 0.199 \\
\hline lgdp1不是Itq1的格兰杰原因 & 7.6355 & 0.022 \\
\hline ltq2不是 $\operatorname{lgdp} 2$ 的格兰杰原因 & 0.3102 & 0.856 \\
\hline $\operatorname{lgdp} 2$ 不是Itq2的格兰杰原因 & 21.4860 & 0.000 \\
\hline ltq3不是 $\operatorname{lgdp} 3$ 的格兰杰原因 & 0.4819 & 0.786 \\
\hline lgdp3不是1tq3的格兰杰原因 & 29.3470 & 0.000 \\
\hline $\operatorname{ltq} 4$ 不是 $\operatorname{lgdp} 4$ 的格兰杰原因 & 5.6328 & 0.060 \\
\hline lgdp4不是1tq4的格兰杰原因 & 18.4050 & 0.000 \\
\hline ltq5不是 $\operatorname{lgdp} 5$ 的格兰杰原因 & 0.3688 & 0.832 \\
\hline lgdp5不是1tq5的格兰杰原因 & 6.7170 & 0.035 \\
\hline ltq6不是lgdp6的格兰杰原因 & 47.0930 & 0.000 \\
\hline lgdp6不是1tq6的格兰杰原因 & 98.2890 & 0.000 \\
\hline ltq7不是lgdp7的格兰杰原因 & 0.2405 & 0.887 \\
\hline lgdp7不是1tq7的格兰杰原因 & 7.6407 & 0.022 \\
\hline ltq9不是lgdp9的格兰杰原因 & 6.0366 & 0.059 \\
\hline lgdp9不是1tq9的格兰杰原因 & 100.50 & 0.000 \\
\hline ltq10不是 $\operatorname{lgdp} 10$ 的格兰杰原因 & 3.0240 & 0.220 \\
\hline $\operatorname{lgdp} 10$ 不是 $\operatorname{ltq} 10$ 的格兰杰原因 & 38.6200 & 0.000 \\
\hline
\end{tabular}

\section{5. 结论及建议}

随着西部大开发战略的开展和实施, 内蒙古各盟市经 济与航空运输均得到了快速发展, 虽然各盟市的发展水平 有着较大差距, 但内蒙古有 7 个盟市的航空运输与经济增 长都存在着长期稳定的均衡关系。呼和浩特市、包头市、 赤峰市、通辽市、呼伦贝尔市、巴彦淖尔市、锡林郭勒盟 和兴安盟这 8 个盟市存在着从实际GDP到航空旅客吞吐量 方向的格兰杰原因, 鄂尔多斯市的实际GDP与航空旅客吞 吐量间具有双向的格兰杰因果关系。相比而言, 通辽市的 区域经济发展更能促进航空运输增长。协整检验与格兰杰 因果检验的结论一致。

总体来说，呼和浩特市、包头市、赤峰市、通辽市、 呼伦贝尔市、巴彦淖尔市、锡林郭勒盟和兴安盟这 8 个盟 市的航空运输发展现状是非常依赖经济增长带动的。对比 而言, 内蒙古地区航空运输发展对经济增长的促进作用非 常有限且相对较小。因此, 加快我国西部地区航空基础设 施建设, 提高西部地区航空运输发展水平, 将为加快实施 西部大开发战略, 扩大对外对内开放, 改善经济环境, 开 放当地旅游资源, 带动其它产业发展, 增进民族团结, 维 护社会稳定, 促进经济发展和社会进步等方面发挥重要作 用。机场与区域经济的和谐发展应当是相互促进的, 它们 其中任何一方的发展都不能离开二者之间的相互关系, 提 出建议如下:

第一, 提高内蒙古航空运输发展水平的根本方法是 促进内蒙古区域经济发展。通常来讲, 越高的社会经济 活动水平将引致更高的航空运输需求水平。在经济发展 过程中, 区域间资源的流动与共享将会更加频繁, 而人 员出行间的交流也将愈加无法满足于耗时较长的陆路运 输。经济增长会在一定程度上促进航空运输的发展, 而 航空运输的发展反过来又会促进经济的增长。

第二, 政府应加强机场及其周边的基础设施建设。如 在机场空中交通管理措施方面, 航空延误问题受到空域资 源不足、管理不完善等因素的影响, 使航空旅客运输的发 展受到阻碍。政府可以通过优化飞行的操作流程、减少飞 机延误, 提高航空运输的便捷性, 以此带动航空客运量的 增加。再如旅客设施服务方面, 应该注意机场大巴通勤车 次、停车场出行、旅客值机办理简便、中转服务优惠、机 场用餐多样等问题是否符合出行旅客需求。

第三, 大力扩展航空市场, 增加航线条数与航班数量。 通过减少飞机在外的停场时间, 提高飞机使用效率, 可以 有效提高航空运输的效率。根据内蒙古地区的实际情况, 一些机场存在航线狭窄、航班数量少等问题, 如截至 2020 年, 与呼和浩特白塔国际机场拥有通航 91 个城市的 154 条 国内外航线相比，乌海机场共有 7 家航空公司开设的 9 条航 线, 通航9座城市, 其中主要航线是通往呼和浩特市白塔 国际机场; 巴彦淖尔市天吉泰机场共有 6 家航空公司开设 的7条航线, 通航8座城市; 赤峰市玉龙机场共有9家航空 公司开设的11条航线, 通航14座城市。政府可通过吸引其 它航空公司加入开设更多的航线与通航城市, 从而达到更 
强的地区通达性, 以获得更多的航空旅客运输需求, 进而 达到促进经济发展的目的。

\section{致谢}

本文为国家自然科学基金（72061027）；内蒙古自治 区高等学校科学研究项目 (NJZZ20149) ; 内蒙古自然科 学基金（2018MS07020）的阶段性成果之一。

\section{参考文献}

[1] 彭语冰,董振强,彭峥.机场与区域经济和谐发展分析[J].商场 现代化,2007(15):207-208。

[2] 谭克晗.空港经济对区域经济的影响——来自广州服务业 的实证证据 [J].知识经济,2010(02):8-9。

[3] 白杨,张杨茗媛.支线机场与区域经济发展: 以江苏省为例 [J]. 中国民航大学学报,2018,36(06):39-44。

[4] 刘兰娟,董万好.基于VAR模型的民航运输业与GDP关系实 证分析 [J].财经研究,2009,35(08):69-78。

[5] 吕丹,薛锋.基于计量经济学的铁路交通基础设施与经济增 长关系研究 $[\mathrm{J}]$. 交通运输工程与信息学 报,2018,16(04):101-108。

[6] 李洁,杨宇翔,庞子帅.基于协整分析的区域交通运输与经济 发展协调性研究 [J]. 交通运输工程与信息学 报,2016,14(02):83-91。

[7] Huddleston J R, Pangotra P P. Regional and local economic impacts of transportation investments [J]. Transportation Quarterly, 1990, 44 (4): 579-594.
[8] Debbage K G. Air transportation and urban-economic restructuring: competitive advantage in the US Caro Linas [J]. Journal of Air Transport Management, 1999, 5 (4): 211-221.

[9] Green R K. A note on airport and economic development [EB/OL]. http://www.bus.wisc.edu, 2008.3.28.

[10] Baker D, Merkert R, Kamruzzaman M. Regional aviation and economic growth: co-integration and causality analysis in Australia [J]. Journal of Transport Geography, 2015, 43 (2): 140-150.

[11] Button K, Yuan J. Airfreight transport and economic development: an examination of causality [J]. Urban Studies, 2013, 50 (2): 329-340.

[12] Kasarda J D, Green J D. Air cargo as an economic development engine: A note on opportunities and constraints [J]. Journal of Air Transport Management, 2015, 11 (6): 459-462.

[13] Marazzo M, Scherre R, Fernandes E. Air transport demand and economic growth in Brazil: A time series analysis[J]. Transportation Research Part E: Logistics \& Transportation Review, 2010, 46 (2): 261-269.

[14] Md Mahbubul H, Rico M. Econometric evidence on the determinants of air transport in South Asian Countries[J]. Transport Policy, 2019, 83 (11): 120-126.

[15] 李艳华.民航运输对于经济增长关系的再实证:2002 2012 年[J].工业技术经济,2015,34(06):10-16。

[16] 申惠,邹平.中国民航业与经济发展协同关系 [J].经济与管理 研究,2016,37(12):98-104。

[17] 王全良.基于动态空间模型的中国临空经济区与腹地区域 经济关系研究[J].地理研究,2017,36(11):2141-2155。

[18] Tolcha T D, Brthen S, Holmgren J. Air transport demand and economic development in sub-Saharan Africa: Direction of causality[J]. Journal of Transport Geography, 2020, 86 (C): 102771. 